\title{
Unusual contents of a scrotal swelling
}

\author{
Gareth Morris-Stiff, ${ }^{1}$ Gavin A Falk, ${ }^{2}$ Daniel Joyce, ${ }^{2}$ Sricharan Chalikonda ${ }^{2}$ \\ 1Department of Surgery, Cwm Taf NHS Trust, LLantrisant, UK; \\ 2Department of Surgery, Cleveland Clinic Foundation, Cleveland, Ohio, USA
}

Correspondence to Gareth Morris-Stiff, garethmorrisstiff@hotmail.com

\section{Summary}

Pseudomyxoma peritonei is an uncommon tumour, usually arising from the appendix. It occasionally presents as a hernia, particularly in men. Here, the case of a 56-year-old male with pseudomyxoma peritonei presenting as a left inguinal hernia is presented, and a brief discussion of the literature on its diagnosis and management is given. The case highlights the importance of carefully evaluating patients with ascites and abdominal wall hernias.

\section{BACKGROUND}

Pseudomyxoma peritonei is a rare neoplasm that is usually associated with vague abdominal symptoms and signs. Presentation as a symptomatic inguinal hernia is uncommon, and in the majority of cases the diagnosis of pseudomyxoma is only appreciated only at the time of hernia repair.

This case report highlights the fact that patients presenting with an inguinal hernia in the presence of ascites should be evaluated clinically and radiologically before considering herniorrhaphy.

\section{CASE PRESENTATION}

A 56-year-old male presented with left-sided scrotal discomfort. He had noticed his left hemi-scrotum enlarging over a period of months but this had not troubled him. He was referred for consideration of a hernia repair at which point doubt was cast on the diagnosis of an inguinal hernia. On further questioning, the patient reported abdominal bloating with an increasing girth but no other gastrointestinal symptoms. Clinical examination identified the presence of intra-abdominal fluid that was believed to be ascites and the scrotum was of a boggy consistency.

\section{INVESTIGATIONS}

A CT scan was performed which confirmed the presence of fluid with direct communication to the left hemi-scrotum (figure 1). Aspiration of the fluid revealed mildly atypical intestinal-type epithelium associated with abundant extracellular mucin, suspicious for pseudomyxoma peritonei.

\section{DIFFERENTIAL DIAGNOSIS}

- Inguinal hernia

- Hydrocele

- Varicocele

- Testicular neoplasm.

\section{TREATMENT}

The patient was referred for consideration of surgery and underwent debulking, peritoneal stripping and instillation of hyperthermic intraperitoneal chemotherapy (HIPEC) with mitomycin C. At laparotomy a large volume of tumour and mucin was identified (figure 2) which was successfully resected leaving minimal residual disease (figure 3).

\section{OUTCOME AND FOLLOW-UP}

The patient made an unremarkable recovery from surgery and there is no evidence of recurrence 6 months following his surgery.

\section{DISCUSSION}

Pseudomyxoma peritonei is an uncommon tumour, usually arising from the appendix, which is characterised by the production of large volume of mucous scattered with occasional malignant cells appearing as a 'jelly belly'. ${ }^{1}$ It is said to occur in approximately 1-2 per million population and is identified in 2 per 10000 laparotomies. ${ }^{2}$ The tumour grows slowly over a period of years and gathers at specific and predictable sites, in particular the greater and lesser omentum, a process known as redistribution phenomenon, as a result of flow and distribution of peritoneal fluid. ${ }^{3}$

The tumours rarely metastasise to the liver or outside the peritoneal cavity but untreated patients develop vague symptoms including nausea, fatigue, abdominal distension, pain and dyspnoea, as a result of visceral compression. ${ }^{4}$ Presentation as an inguinal hernia has previously been documented as a result of mucin traversing the processus vaginalis. A review of 217 patients with pseudomyxoma in the Washington Cancer Institute database indicated that a hernia was the fourth most common mode of presentation, seen in 30 individuals representing $25 \%$ of male and $4 \%$ of female patients. ${ }^{5}$ Ten patients had umbilical hernias, and the remaining 20 were inguinal with $2 / 3$ of hernias seen on the right hand side. ${ }^{5}$ It is unclear from the paper as to whether the pseudomyxoma was diagnosed before the repair of hernia or as a result of identifying mucin in the sac at the time of surgery. In a subsequent paper the group reported on 20 patients with pseudomyxoma diagnosed on the basis of identification of mucin in the hernia sac at the time of repair. ${ }^{6}$ In 16 of the patients, a laparotomy was performed 


\section{BMJ Case Reports}

following the identification of mucin with a variety of additional procedures. A detailed review of the literature identified only two cases, such as ours, in which atypical features of the hernia together with vague gastrointestinal symptoms lead to preoperative evaluation and diagnosis of pseudomyxoma peritonei. ${ }^{7}$

Once a diagnosis of pseudomyxoma is made, the patient should be evaluated with CT to determine the extent of the

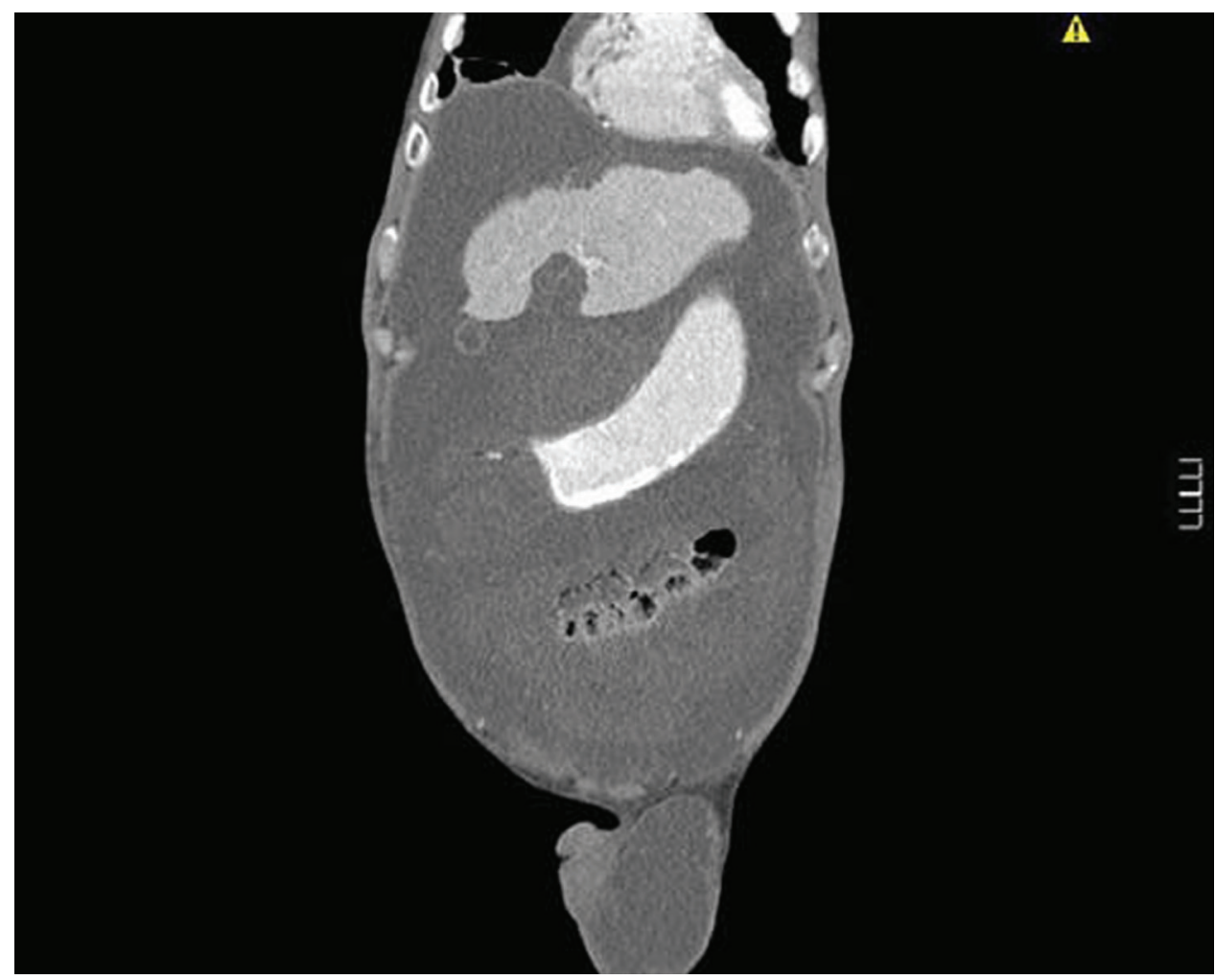

Figure 1 CT scan showing widespread intra-abdominal fluid that tracks into the inguinoscrotal region.

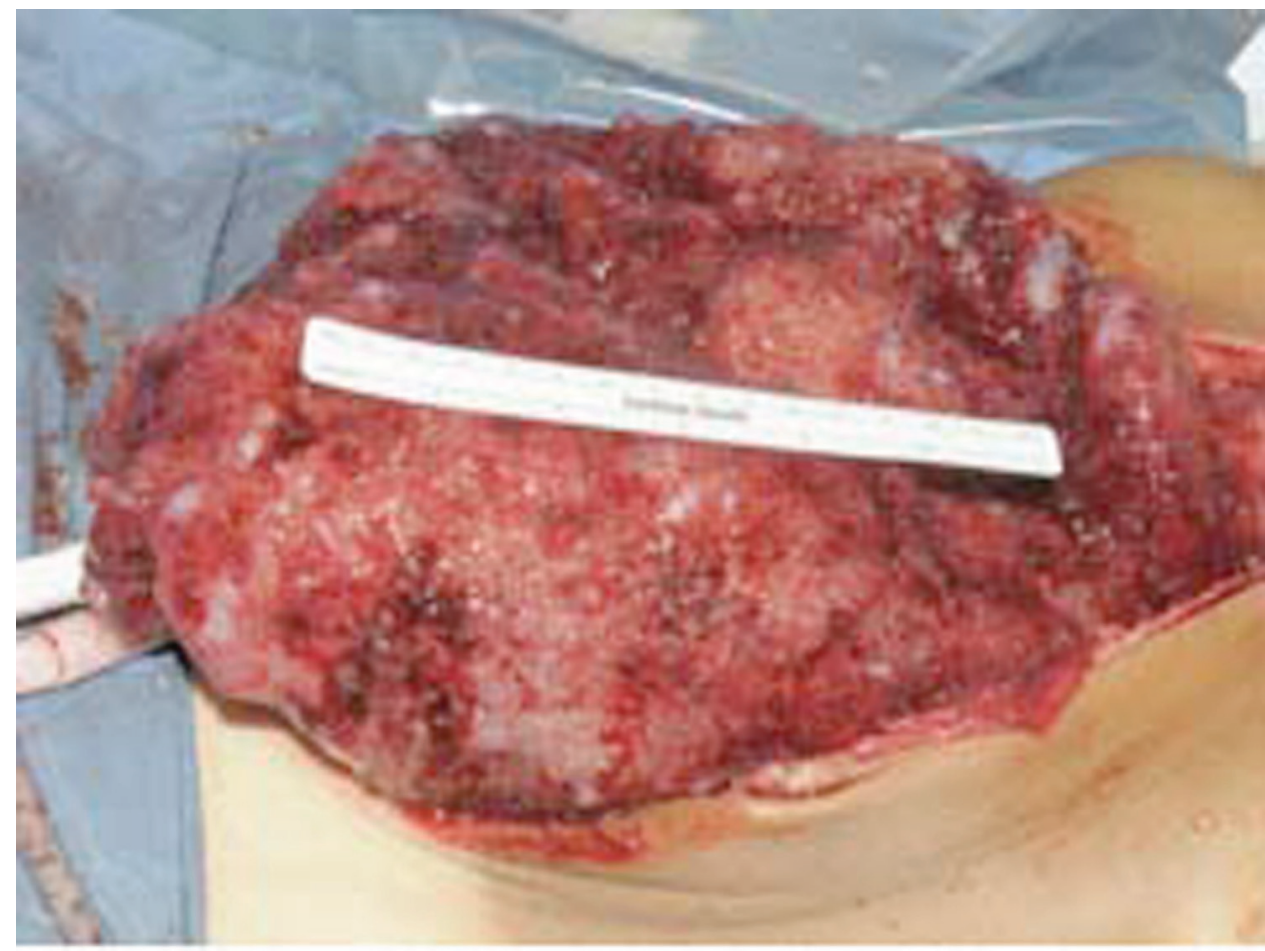

Figure 2 Intraoperative findings at laparotomy - large tumour with abundant mucin production. 


\section{BMJ Case Reports}

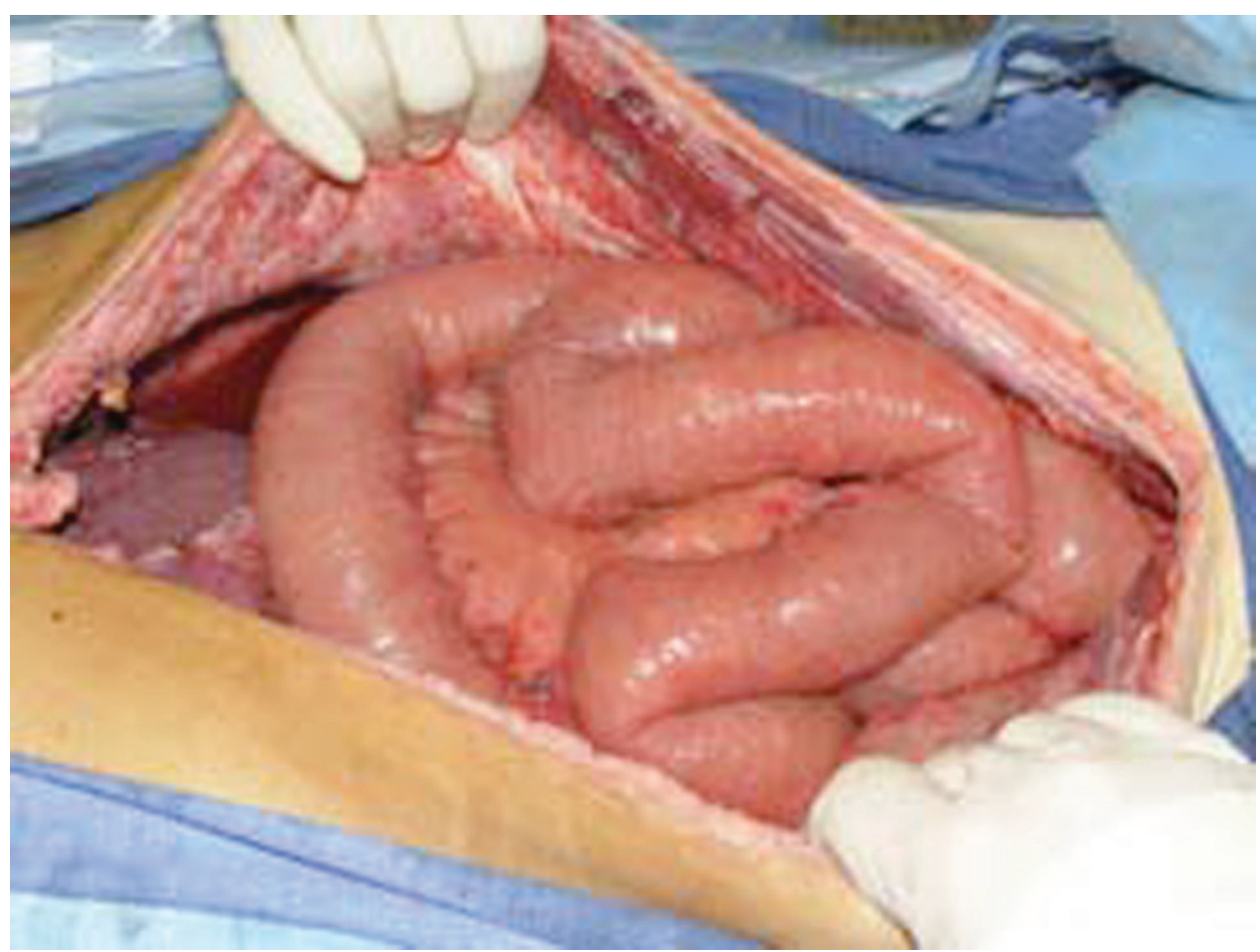

Figure 3 Post debulking and peritoneal stripping.

disease, tumour markers should be sent, and the patient referred to a specialist treatment centre. The current treatment of pseudomyxoma is largely based on the work of Sugarbaker and colleagues from Washington who have defined the current standards of care which consist of a combination of peritonectomy and debulking of all gross disease with visceral resection as indicated together with HIPEC using mitomycin $\mathrm{C}$. This approach has led 5-year survival rates in excess of $70 \% .{ }^{9}$ The outcome of this approach is closely linked to the estimated volume of residual disease. ${ }^{10}$

\section{Learning points}

- Pseudomyxoma peritonei is the result of an uncommon tumour, usually mucinous cystadenocarcinoma of the appendix.

- Patients with pseudomyxoma peritonei may present with increasing abdominal girth $(40 \%)$, bilateral or unilateral ovarian tumours $(20 \%)$, hernia sac tumours $(20 \%)$, appendicitis-like syndrome $(10 \%)$ and infertility $(10 \%)^{11}$

- An abdominal wall hernia is a relatively common mode of presentation particularly in men.

- The current standard of care involves cytoreductive surgery with resection of all gross disease followed by HIPEC.

- Patients presenting with an abdominal wall hernia and concomitant ascites should be evaluated radiologically and otherwise before herniorrhaphy.
Competing interests None.

Patient consent Obtained.

\section{REFERENCES}

1. Sugarbaker PH, Ronnett BM, Archer A, et al. Pseudomyxoma peritonei syndrome. Adv Surg 1996;30:233-80.

2. Hinson FL, Ambrose NS. Pseudomyxoma peritonei. Br J Surg 1998;85:1332-9.

3. Sugarbaker PH. Pseudomyxoma peritonei. A cancer whose biology is characterized by a redistribution phenomenon. Ann Surg 1994;219:109-11.

4. Sherer DM, Abulafia 0, Eliakim R. Pseudomyxoma peritonei: a review of current literature. Gynecol Obstet Invest 2001;51:73-80.

5. Esquivel J, Sugarbaker PH. Clinical presentation of the Pseudomyxoma peritonei syndrome. Br J Surg 2000;87:1414-18.

6. Esquivel J, Sugarbaker PH. Pseudomyxoma peritonei in a hernia sac: analysis of 20 patients in whom mucoid fluid was found during a hernia repair. Eur J Surg Oncol 2001;27:54-8.

7. Hosaka A, Masaki Y, Yamasaki K, et al. Pseudomyxoma peritonei presenting with femoral hernias and peritonitis. J Gastrointest Surg 2007;11:1576-8.

8. Lee YT, Wu HS, Hung MC, et al. Ruptured appendiceal cystadenoma presenting as right inguinal hernia in a patient with left colon cancer: a case report and review of literature. BMC Gastroentero/ 2006;6:32.

9. Sugarbaker PH. New standard of care for appendiceal epithelial neoplasm and pseudomyxoma peritonei syndrome? Lancet Oncol 2006; 7:69-76.

10. Jacquet $\mathbf{P}$, Sugarbaker PH. Current methodologies for clinical assessment of patients with peritoneal carcinomatosis. J Exp Clin Cancer Res 1996; 15:49-58.

11. Sugarbaker PH. Pseudomyxoma peritonei. Cancer Treat Res 1996;81:105-19. 


\section{BMJ Case Reports}

This pdf has been created automatically from the final edited text and images.

Copyright 2011 BMJ Publishing Group. All rights reserved. For permission to reuse any of this content visit http://group.bmj.com/group/rights-licensing/permissions.

BMJ Case Report Fellows may re-use this article for personal use and teaching without any further permission.

Please cite this article as follows (you will need to access the article online to obtain the date of publication).

Morris-Stiff G, Falk GA, Joyce D, Chalikonda S. Unusual contents of a scrotal swelling. BMJ Case Reports 2011;10.1136/bcr.03.2011.4023, date of publication

Become a Fellow of BMJ Case Reports today and you can:

- Submit as many cases as you like

- Enjoy fast sympathetic peer review and rapid publication of accepted articles

- Access all the published articles

- Re-use any of the published material for personal use and teaching without further permission

For information on Institutional Fellowships contact consortiasales@bmjgroup.com

Visit casereports.bmj.com for more articles like this and to become a Fellow 